\title{
Splenic abscess leading to spontaneous splenic rupture
}

\author{
Annum A. Bhullar, ${ }^{1}$ Caleb P. Canders, ${ }^{2}$ Amir Rouhani, ${ }^{1}$ Steven Lai ${ }^{1}$ \\ ${ }^{1}$ Department of Emergency Medicine, Olive View-UCLA Medical Center, Sylmar, CA; \\ ${ }^{2}$ Department of Emergency Medicine, Santa Clara Valley Medical Center, San Jose, CA, USA
}

\begin{abstract}
Spontaneous, atraumatic rupture of the spleen is an uncommon but potentially fatal cause of acute abdominal pain. Splenic abscesses are equally rare and can be a risk factor for spontaneous splenic rupture. We present a 45 -year-old man with no past medical or surgical history who presented with acute worsening of left upper abdominal pain that had been present for months, who was discovered to have a ruptured spleen. Splenic abscess was discovered intra-operatively and was thought to have developed after dental work. Recognizing presenting features of spontaneous splenic rupture and understanding its potential causes, such as splenic abscesses, may prevent delayed or missed diagnosis and guide treatment, which typically includes emergent splenectomy.
\end{abstract}

Correspondence: Caleb P. Canders, MD, Department of Emergency Medicine, Santa Clara Valley Medical Center, 751 S Bascom Ave, 95128 San Jose, CA, USA.

Tel.: 310.7940785 - Fax: 310.7940599 .

E-mail: ccanders@mednet.ucla.edu

Key words: Splenic abscess; splenic rupture; splenic hemorrhage; splenectomy.

Contributions: $\mathrm{AAB}$ and $\mathrm{CPC}$ drafted the manuscript. $\mathrm{AR}$ and $\mathrm{SL}$ revised the manuscript critically for important intellectual content.

Conflict of interest: No one. This work was not supported by any grant.

Availability of data and materials: All data underlying the findings are fully available.

Ethics approval and consent to participate: No ethical committee approval was required for this case report by the Department, because this article does not contain any studies with human participants or animals. Informed consent was obtained from the patient included in this study.

Consent for publication: The patient gave his written consent to use his personal data for the publication of this case report and any accompanying images.

Received for publication: 23 June 2020.

Accepted for publication: 11 November 2020.

This work is licensed under a Creative Commons Attribution 4.0 License (by-nc 4.0).

${ }^{\circ}$ Copyright: the Author(s), 2021

Licensee PAGEPress, Italy

Emergency Care Journal 2021; 17:9204

doi:10.4081/ecj.2021.9204

\section{Introduction}

Spontaneous, atraumatic splenic rupture is an uncommon but potentially fatal cause of acute abdominal pain. It can be caused by a number of underlying processes, including splenic abscess, which itself is a rare condition with an often-insidious course and high mortality rate. Early recognition of splenic abscess and rupture can help to expedite diagnosis and management, which is typically operative.

\section{Case Report}

A 45-years-old male with no past medical or surgical history presented with two months of subjective fevers and intermittent left upper abdominal pain, which had intensified for the past two days. It was associated with multiple episodes of watery emesis for one day and a 25-pounds weight loss over the past month. Six months prior to symptom onset, he had undergone placement of a dental bridge. He took no medications. He had a 20 pack years history of smoking. He was born in Mexico and had been living in the U.S. for the past 15 years.

On examination, the patient had a heart rate of 130 beats per minute, blood pressure of $117 / 66 \mathrm{mmHg}$, respiratory rate of 22 breaths per minute, oxygen saturation of $94 \%$ on room air, and temperature of 37.1 degrees Celsius. He had sinus tachycardia (without extra heart sounds), decreased breath sounds at the left lung base, left upper abdominal tenderness, and splenomegaly. The remainder of his examination was unremarkable. Blood tests were notable for: white blood cell count $30 \mathrm{x}$ cells $/ \mathrm{mm}^{3}$ (normal 3.8$10.9 \times 10^{3}$ cells $/ \mathrm{mm}^{3}$ ), bicarbonate $20 \mathrm{mmol} / \mathrm{L}$ (normal 22-30 $\mathrm{mmol} / \mathrm{L}$ ), creatinine $1.83 \mathrm{mg} / \mathrm{dL}$ (normal $0.6-1.2 \mathrm{mg} / \mathrm{dL}$ ), and BUN $33 \mathrm{mg} / \mathrm{dL}$ (normal 8-24 mg/dL). Liver enzyme and lipase levels were normal. A chest radiograph demonstrated a left lower pleural effusion (Figure 1). A non-contrast CT of the abdomen and pelvis revealed an enlarged, ruptured spleen, with a large hematoma within the spleen (Figure 2). The patient received intravenous fluids, piperacillin-tazobactam, and metronidazole. Emergent exploratory laparotomy confirmed splenic rupture and the patient subsequently underwent open splenectomy, during which he was found to have a splenic abscess with peritonitis. Intraperitoneal cultures grew Streptococci viridans and Streptococcus gordonii, which are part of the oral flora and atypical causes of splenic abscesses. It was speculated that the dental work he had undergone six months prior was causative.

\section{Discussion}

Splenic abscesses are rare, with an estimated incidence of $0.05-0.07 \% .^{1,2}$ The most common causes are septic emboli from infective endocarditis. ${ }^{3}$ Other predisposing factors include prior 
splenic injuries, immunosuppression, bacteremia, and spread from contiguous organs (e.g. pyelonephritis). The three most common presenting signs of splenic abscesses are fever (90\% patients), abdominal pain (31-60\% patients), and splenomegaly $(50 \%$ patients), although only one-third of patients present with the complete triad. ${ }^{4}$ Splenic abscesses in the upper pole may irritate the diaphragm, causing diaphragm elevation, pleural effusion, and pneumonia. Given the vague and insidious nature of symptoms, diagnosis is often delayed or missed; the mean duration of symptoms from onset until diagnosis is 27 days. ${ }^{4}$ Leukocytosis is seen in less than half of patients. ${ }^{4} \mathrm{CT}$ and MRI are more accurate than ultrasound at diagnosing splenic abscesses..$^{2,4,5}$ Staphylococci and Streptococci species are the most common organisms isolated from splenic abscesses; however, anaerobic bacteria, tuberculosis, and fungi have also been reported. ${ }^{6}$ Blood cultures are negative in more than half of patients. $^{7}$ Antibiotics should provide coverage against anaerobes and aerobes. Most patients undergo splenectomy, although percutaneous drainage can be successful in some patients. ${ }^{3}$ Delays in diagnosis have been shown to worsen prognosis; mortality ranges $0-25 \%$ in promptly treated patients and $100 \%$ in untreated patients. ${ }^{5,8}$

Atraumatic splenic rupture is another exceedingly rare diagnosis that has a mortality of $15 \% .{ }^{9}$ As defined in the surgical literature, cases of "spontaneous rupture" must meet four criteria: i) absence of trauma, ii) absence of disease in other organs that could cause splenic rupture, iii) absence of splenic adhesions/scarring (suggestive of previous rupture), and iv) aside from hemorrhage, the spleen is grossly and histologically normal. ${ }^{10}$ Causes of spontaneous splenic rupture include bacterial infections (e.g. splenic abscess, as in our case), viral infections, hematologic malignancies, splenic neoplasms, and non-malignant infiltrative processes (e.g. amyloidosis). ${ }^{11}$ Approximately $95 \%$ of patients with spontaneous splenic rupture have splenomegaly and left upper abdominal tenderness. ${ }^{12}$ Diaphragmatic irritation may also cause left shoulder pain (Kehr's sign). CT is the preferred imaging to diagnose splenic rupture and has a sensitivity and specificity greater than $95 \%{ }^{13}$ Most patients with splenic rupture undergo splenectomy, although transcatheter embolization may be an option in some patients.

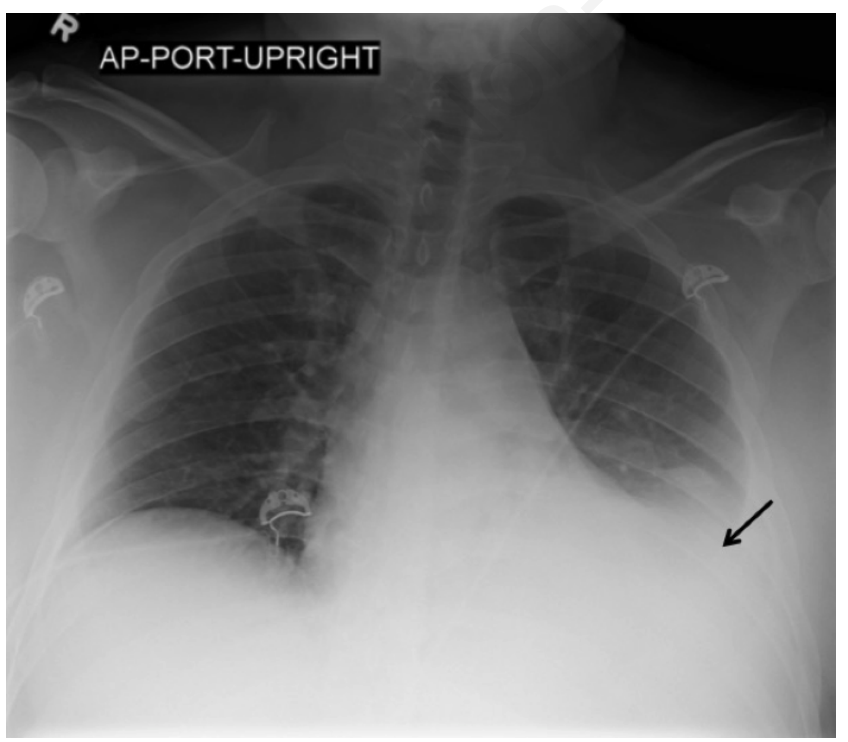

Figure 1. Anteroposterior chest $\mathrm{X}$-ray demonstrates an effusion in the left lower lobe (arrow).

\section{Conclusions}

Spontaneous splenic rupture is an uncommon but potentially fatal cause of acute abdominal pain that typically requires emergent operative repair. Patients commonly present with left upper abdominal pain and signs of peritonitis and hypovolemic shock. Early recognition and management of spontaneous splenic rupture and its inciting factors, including splenic abscess, can be lifesaving.
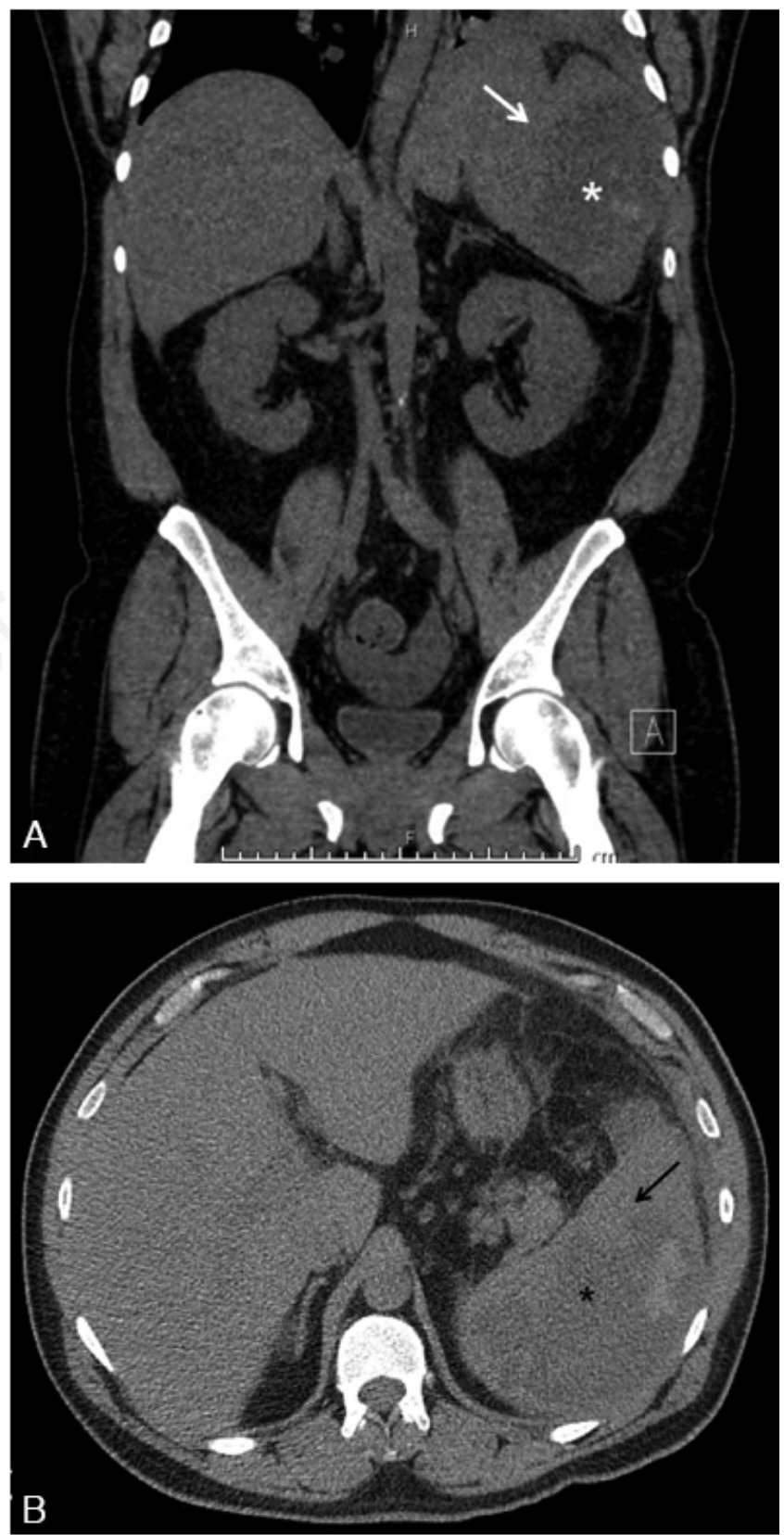

Figure 2. Coronal (A) and axial (B) computed tomography images show splenomegaly (arrow) with a $6.7 \mathrm{~cm}$ by $11.4 \mathrm{~cm}$ hematoma within the spleen (star). 


\section{References}

1. Chang KC, Chuah SK, Changchien CS, et al. Clinical characteristics and prognostic factors of splenic abscess: a review of 67 cases in a single medical center of Taiwan. World J Gastroenterol 2006;12:460-4.

2. Nelken N, Ignatius J, Skinner M, et al. Changing clinical spectrum of splenic abscess. Am J Surg 1987;154:27-34.

3. Alnasser SA, Mindru C, Preventza O, et al. Successful conservative management of a large splenic abscess secondary to infective endocarditis. Ann Thorac Surg 2019;107:e235-e237.

4. Chiang IS, Lin TJ, Chiang IC, et al. Splenic abscesses: review of 29 cases. Kaohsiung J Med Sci 2003;19:510-5.

5. Gadacz TR. Splenic abscess. World J Surg 1985;9:410-5.

6. Brook I, Frazier EH. Microbiology of liver and spleen abscesses. J Med Microbiol 1998;47:1075-80.

7. Green BT. Splenic abscess: report of six cases and review of the literature. Am Surg 2001;67:80-5.

8. Nieciecki M, Kozuch M, Czarnieck Ci, et al. How to diagnose splenic abscesses? Acta Gastroenterol Belg 2019;82:421-6.

9. Renzulli P, Hostettler A, Schoepfer AM, et al. Systematic review of atraumatic splenic rupture. Br J Surg 2009;96:111421.

10. Orloff MJ, Peskin GW. Spontaneous rupture of the normal spleen: a surgical enigma. Int Abstr Surg 1958;106:1-11.

11. Gedik E, Girgin S, Aldemir M, et al. Non-traumatic splenic rupture: report of seven cases and review of the literature. World J Gastroenterol 2009;14:6711-6.

12. Mirvis SE, Soto JA, Shanmuganathan K, et al. Problem Solving in Emergency Radiology. Saunders.

13. Jeffrey RB, Laing FC, Federle MP, et al. Computed tomography of splenic trauma. Radiology 1981;141:729-32. 